\title{
Standardized Patient Reported Outcomes Do Not Capture Functional Deficits of Patients Following Contemporary Total Knee Replacement: Descriptive Study
}

\author{
Ashley Y Disantis ${ }^{1}$, Sara R Piva ${ }^{2 *}$ and James J Irrgang ${ }^{3}$ \\ ${ }^{1} P T$, DPT, OCS, CSCS, Outpatient Physical Therapist.
}

${ }^{2}$ PhD, PT, Associate Professor, Co-director of the Physical Therapy Clinical and Translational Research Center.

${ }^{3} P T, P h D, A T C, F A P T A$, Chair and Professor, Dept of Physical Therapy.

Received: January 01, 2018; Accepted: January 22, 2018; Published: February 05, 2018

*Corresponding author: Sara R. Piva, Bridge side Point 1, 100 Technology Drive, Suite 210, Pittsburgh, PA 15219-3130. Tel: (412) 383-6712; Fax: (412) 648-5970;Email: spiva@pitt.edu

\begin{abstract}
Background: The physical function subscale of the Western Ontario and McMaster Universities Osteoarthritis Index (WOMAC-PF) is widely used and endorsed by professional organizations for patients with knee osteoarthritis. Its use post total knee replacement (TKR) has been challenged as it may not represent the high level of functional performance that is expected by patients who undergo contemporary TKR with more advanced techniques and care pathways.
\end{abstract}

Objective: To assess whether the items of the WOMAC-PF reflect the activity limitations identified by patients following TKR.

Design: Data for this descriptive study were obtained from baseline assessments of a randomized clinical trial comparing exercise interventions following TKR.

Methods: Participants completed the WOMAC-PF and identified activity limitations in the Canadian Occupational Performance Measure (COPM) in the same day. The responses to both questionnaires were compared.

Results: This investigation included 50 participants (36 women, mean age $63.8 \pm 6.7$ ). The WOMAC-PF failed to capture $50 \%$ of the activity limitations identified by participants in the COPM. These activities included kneeling, squatting, carrying/lifting items, strength/endurance exercise, floor transfer, lower extremity exercise, walking up/down hills, yard work, climbing a ladder, driving, managing the environment, carrying objects up/down stairs, gait initiation, balance, and going up/down curbs. Only one activity on the WOMAC$\mathrm{PF}$ (going shopping) was not identified by participant responses on the COPM.

Limitations: Participants were included if they had TKR between 3 and 6 months prior, which may limit generalizability to those immediately after TKR, and the study sample was relatively small.

Conclusions: In individuals following TKR, the WOMAC-PF failed to represent a subset of higher level, more physically demanding activities that were identified as important by patients following TKR.

\section{Introduction}

Total knee replacement (TKR) is one of the most used and fastest growing surgical interventions worldwide (1). Even though this procedure has been shown to improve quality of life and reduce pain, deficits in physical function are known to persist after surgery $(2,3)$. In everyday practice, clinicians rely on patient-reported outcome measures (PROMs) to quantify the trajectory of functional recovery of these patients.

The Western Ontarioand McMaster Universities Osteoarthritis Index (WOMAC) is one of the PROM designed for hip and knee osteoarthritis(4-7). The WOMAC one of the most frequently used PROM in patients status post TKR. Despite being widely used, the value of the WOMAC in TKR has been challenged (8-11). One of the problems with this PROM has been discrepancies between the scores on the WOMAC physical function subscale (WOMAC$\mathrm{PF}$ ) and physical performance scores in patients post TKR. Several studies described that while patients tend to perceive and report improvements in their ability to complete functional tasks on the WOMAC-PF after surgery, their performance during physical tasks, such as stair climbing and walking, actually worsen (10-12). The discrepancies between the WOMAC-PF and performance-based test scores can be partially explained by the effect of pain experience on patients' perceived ability to move around $(10,11,14,15)$.

Another explanation for the discrepancies between the WOMAC-PF and performance measures in TKR may be that the items on the WOMAC-PF may not adequately represent the activities that are relevant to this population. It has been shown that as many as $52 \%$ of patients following TKR have difficulty with functional activities such as kneeling, squatting, turning laterally, carrying loads, lower extremity strengthening activities, cutting and turning, dancing, and gardening (16); none of which are depicted on the WOMAC-PF. The Osteoarthritis Research Society International (OARSI) has also identified a group of activities that are relevant to patients following TKR, including rising from a stool without hand support, sitting down in a chair, lifting and carrying objects, putting on socks/footwear, getting in and out of 
bed, and several walking activities such as walking long distances, on different surfaces, down stairs and upstairs, around/over obstacles, and turning whilst walking (17). Only about half of these activities are included in the WOMAC-PF subscale. As such, the WOMAC-PF scale may be susceptible to under-representation of the construct of physical function regarding activities that are important to patients following TKR. Additionally, a review of outcome measures for knee osteoarthritis cautioned in the use of the WOMAC-PF in more physically active patients because it does not include demanding functional tasks (4).

When the WOMAC was developed in the early 1980's, its content validity was properly ensured by surveying a large number of patients with hip and knee osteoarthritis, reviewing existing outcome scales, and gathering input from clinicians experienced in rheumatic diseases (18). However, in the last three decades, there have been several advancements in TKR prosthesis design, surgical technique, anesthesia, and pathways of care. These advancements resulted in a much faster and improved functional recovery for these patients, and the items on the WOMAC may no longer represent the limitations of those patients. Despite the fact that in the late 1990s the WOMAC items were used to form the Knee injury and Osteoarthritis Outcome Score (KOOS), the items that form the function subscale of the KOOS are the same as the WOMAC-PF (19). To that end, in the context of a recent randomized study comparing exercise programs for patients after TKR, patients were asked to identify daily activities that they had trouble performing and considered important, and also to complete the WOMAC (20). In this study, we proposed to identify daily activities that are important and generally limited in patients who undergo TKA and to investigate whether items included on the WOMAC-PF adequately represent the activity limitations of these patients.

\section{Methods}

Data for this descriptive study were obtained from baseline assessments of a randomized clinical trial on exercise intervention post TKR (20). Data collection took place from October 2011 to August 2013 in the clinic of the Department of Physical Therapy at the University of Pittsburgh. All participants signed an informed consent document approved by the University of Pittsburgh Institutional Review Board (IRB). The study protocol was also approved by the same IRB.

Participants were eligible to enter the study if they underwent a unilateral TKR 3 to 6 months prior, were able to obtain written medical clearance to participate in the study, were English speakers, and were older than 50 years. Exclusion criteria included bilateral TKR or a revision surgery, previous hip or ankle replacement, inability to bear weight on the surgical knee, more than 2 falls in the past year, any uncontrolled medical condition that would prevent safe participation in exercise, diagnosis of a neurological condition that affects locomotion, malignancy, participation in regular exercise, and another surgery within the previous 6 months.

\section{Clinical Measures}

Participants attended one testing session where they completed study questionnaires administered by trained clinicians. Demographic and biomedical information were collected first and included age, gender, race, level of education, marital status, height, weight, time since surgery, chronicity of knee symptoms, and number of chronic diseases besides osteoarthritis. After that, the WOMAC was completed followed by the Canadian Occupational Performance Measure (COPM).

The WOMAC is a standardized outcome measure widely used to assess function in patients with hip and knee osteoarthritis $(5,18)$. All three subscales of the WOMAC (stiffness, pain, and physical function) were completed by the participants; however, only the 17 items from physical function subscale (WOMAC$\mathrm{PF}$ ) were used in this investigation. The items on the WOMAC are scored on a 5-point Likert scale from 0 (no difficulty) to 4 (extreme difficulty). Scores of the WOMAC-PF range from 0 to 68 , with higher scores representing less physical function. We used the version LK 3.1. The WOMAC has demonstrated good reliability and validity in patients with knee osteoarthritis $(6,18$, 21-23).

To identify the functional activities that were limited and important to the patients, we administered the COPM. The COPM is a validated patient-centered outcome measure that captures a patient's self-perception of functional performance in everyday living $(24,25)$. The COPM was administered by having participants identify and prioritize five activities that were restricted or impacted their performance in everyday living secondary to their knee osteoarthritis or TKR in the areas of selfcare, productivity, and leisure. Participants were asked to selfreflect and rank the importance, performance, and satisfaction of each selected activity on a 10-point scale. The importance scale is rated as 1 (not important at all) to 10 (extremely important), the performance scale is rated as 1 (not able to do it) to 10 (able to do it extremely well), and the satisfaction scale is rated as 1 (not satisfied at all) to 10 (extremely satisfied). Values for the three raw scores of importance, performance, and satisfaction were used for this investigation. Of note, we did not compute the summary scores for the COPM; we only used the COPM to determine the activities that patients identified as important to them. The COPM has been previously validated in patients with various conditions, including but not limited to stroke, rheumatic diseases, osteoarthritis, and other musculoskeletal disorders; and has demonstrated very good reliability and validity (24-26).

\section{Statistical Analyses}

Participant characteristics were described by means with standard deviations and frequencies with percentages, depending on the nature of the variable. To enable comparison between the COPM and the WOMAC-PF, analysis was done at the level of the individual activities identified by the participants on the COPM and the individual items of the WOMAC-PF (we did not use summary scores). To accomplish that, the items defined by the participants on the COPM were organized into activity categories (e.g., sitting, walking, floor transfer) that encompassed all individual participant stated descriptions. For example, individual participants' descriptions for sitting included 
phrases such as "sitting for a length of time," "sitting on a hard chair," and "sitting" and therefore were all consolidated into the activity category "sitting." For each activity category of the COPM, we calculated the frequency (and percentage) of participants that identified those activities, and the average of importance, performance, and satisfaction scores for each activity category. We also calculated the frequencies (and percentages) for each response on the 5-point Likert scale for the 17 WOMAC-PF items.

To compare the activities captured by the COPM with the individual items of the WOMAC-PF, the COPM activity categories were matched to a corresponding WOMAC-PF item, when available. We used t-tests to determine whether the COPM importance, performance, and satisfaction scores were different for the activities that had a WOMAC-PF match compared to the activities without a match.

To assess whether activities more frequently identified were more relevant to participants than those identified less frequently, the COPM activity categories were classified as identified by $10 \%$ or more of participants, or identified by less than $10 \%$ of the sample. T-tests were used to compare the average scores of importance, performance, and satisfaction for the items identified by $10 \%$ or more of participants to those identified by less than $10 \%$ of participants. IBM-SPSS version 23 was used for all calculations.

\section{Results}

Data on 50 participants were available for analysis. The mean age of the sample was $63.8 \pm 6.7$ years and $68 \%$ were female (Table 1). Although all participants were asked to identify 5 activities that were functionally limited, of the 50 participants, 47 were able to identify 5 functionally limiting activities. One participant identified only one activity as being problematic while two participants identified only three activities as functionally limited; for a total of 242 activities reported on the COPM by the 50 participants. From those, 3 participants reported pain location rather than an activity per se (i.e., "tenderness over inner part of knee," "back pain") and 3 participants selected a hand/upper extremity task rather than activity affected by knee osteoarthritis of the TKR, and these responses were not included in the analysis. Therefore, a total of 236 activity limitations identified by the 50 participants in the COPM were included in the analysis.

The 236 activity limitations identified in the COPM were organized into 30 categories that encompassed all participant stated activity descriptions (Table 2). From the30 activity categories, 15 could be matched to a corresponding item in the WOMAC-PF and 15 (50\%) could not be matched (Table 3). In terms of total frequency, the 15 matched items corresponded to 161 of the 236 (68\%) functional activities identified on the COPM that were represented in the WOMAC-PF.

The comparison of the COPM scores between the activity categories that had or did not have WOMAC-PF matched items was not statistically significant nor clinically meaningful, indicating that the participants considered the relevance of the activities with or without a match to be similar. The means
Table 1: Demographic and Biomedical Characteristics of Study Participants

\begin{tabular}{|c|c|}
\hline \multicolumn{2}{|c|}{ Participants Characteristics $(n=50)$} \\
\hline Mean age $\pm S D, y$ & $63.8 \pm 6.7$ \\
\hline Gender -Number of Female (\%) & $34(68)$ \\
\hline Mean height \pm SD, $\mathrm{cm}$ & $170 \pm 10$ \\
\hline Mean weight \pm SD, kg & $82.8 \pm 13.2$ \\
\hline \multicolumn{2}{|l|}{ Months Since Surgery- N (\%) } \\
\hline 3-3.9 & $15(30)$ \\
\hline $4-4.9$ & $20(40)$ \\
\hline $5-6$ & $15(30)$ \\
\hline \multicolumn{2}{|l|}{ Years with knee symptoms- N (\%) } \\
\hline$<5$ & $22(44)$ \\
\hline $5-10$ & $14(28)$ \\
\hline$>10$ & $14(28)$ \\
\hline \multicolumn{2}{|l|}{ Ethnicity- N (\%) } \\
\hline African American & $5(10)$ \\
\hline White & $45(90)$ \\
\hline \multicolumn{2}{|l|}{ Level of Education- N (\%) } \\
\hline High School & $19(38)$ \\
\hline College & $18(36)$ \\
\hline Post Graduate & $13(26)$ \\
\hline \multicolumn{2}{|l|}{ Marital Status- N (\%) } \\
\hline Married & $30(50)$ \\
\hline Divorced & $14(28)$ \\
\hline Other & $6(12)$ \\
\hline \multicolumn{2}{|l|}{ Number of Co morbidities- $\mathrm{N}(\%)$} \\
\hline $0-1$ & $18(36)$ \\
\hline $2-4$ & $30(50)$ \\
\hline$>5$ & $6(14)$ \\
\hline $\begin{array}{l}\text { WOMAC*-mean Physical Function subscale } \pm \\
\text { SD }\end{array}$ & $18.6 \pm 9.9$ \\
\hline
\end{tabular}

of importance scores for matched items and unmatched items were $8.4 \pm 0.9$ and $7.9 \pm 1.3$ respectively $(t=-1.32, p=0.198)$. The means of performance scores for matched items were $4.9 \pm 0.9$ and $4.7 \pm 1.5$ for unmatched items $(t=-.279, p=0.783)$. The means of satisfaction scores for matched and unmatched items were $3.6 \pm 0.9$ and $3.7 \pm 1.8$ respectively( $\mathrm{t}=.205, \mathrm{p}=0.839)$ (these averages are not shown in Table 3 ).

Of the 30 COPM activity categories, 19 were identified by at least $10 \%$ of participants, whereas 11 activity categories were identified by less than $10 \%$ of participants (Table 3). The comparison of the COPM scores between the activities identified by at least $10 \%$ of participants (shaded rows in Table 3) and the 
Table 2: Canadian Occupational Performance Measure (COPM) Activity Categories with Patient Descriptions*

\begin{tabular}{|c|c|c|}
\hline Down Stairs & Up/Down Stairs & Up Stairs \\
\hline Down stairs & Up/down stairs & Stair climbing \\
\hline Going down stairs & Steps & Going up stairs \\
\hline Walk down stairs & Walking up and down steps & Climbing up steps \\
\hline Coming down stairs & Handling stairs & Upstairs \\
\hline Down steps & Stairs & Step Up \\
\hline Downstairs & Walking stairs & Up steps \\
\hline Standing & Sit-to-Stand Transfer & Kneeling \\
\hline Standing & Arising from sitting & Kneeling \\
\hline Standing too long & Getting up-chair & Kneel \\
\hline Standing long periods & Sitting down action & Knee down \\
\hline Standing in one position & Getting up from sitting & \\
\hline Standing in place & Getting up from chair or sofa & \\
\hline Long periods of standing & Getting up after sitting for long & \\
\hline Standing a length of time & Standing from sitting position & \\
\hline Standing in one place for 15 minutes & Getting out of chair & \\
\hline \multirow[t]{3}{*}{ Standing after sitting long } & Standing up from chair & \\
\hline & Getting up & \\
\hline & Rising from sitting after 1 hour & \\
\hline Walking & Squatting & Bending/Flexibility \\
\hline Walking & Squatting & Bending surgical knee \\
\hline Walking to car & Bending down & Bend \\
\hline Walking a distance & Stoop down & Bending/flexibility \\
\hline Walking fast & Crouching & Bending \\
\hline Walking for a long time & & Knee up \\
\hline \multicolumn{3}{|l|}{ Walking long period } \\
\hline \multicolumn{3}{|l|}{ Not being able to walk 4 miles a day } \\
\hline \multicolumn{3}{|l|}{ Walking more than 2 blocks } \\
\hline Car Transfer & Carrying/Lifting Items & Sitting \\
\hline Getting out of car & Lifting from floor & Sitting too long \\
\hline Enter car & Carrying heavy items & Sitting for a length of time \\
\hline In/out of car on passenger side & Lifting & Sitting long periods \\
\hline In and out of car & Lifting basket & Sitting hard chair \\
\hline Getting out of car & Carrying groceries & Sitting \\
\hline In car and out & Carrying boxes or bags & \\
\hline \multicolumn{3}{|l|}{ Pushing off car to stand } \\
\hline Dressing/Socks & Household Chores/Recreational Activity & Strength/Endurance \\
\hline Putting on shoes & Washing kitchen and bathroom floor & Stamina issues \\
\hline Putting on sock & Housework & Physical stamina \\
\hline Putting on panty hose & Reaching for anything & Endurance \\
\hline
\end{tabular}




\begin{tabular}{|c|c|c|}
\hline Certain movements (putting on pants) & Household chores & Any long term activity \\
\hline \multirow[t]{2}{*}{ Putting on my socks } & Painting & Lack of stamina \\
\hline & Playing pipe organ & Strength \\
\hline Floor Transfer & Lower Extremity Exercise & Tub Transfer \\
\hline Getting up/down from floor & Leg lifts & Bathtub out \\
\hline Getting off floor & Riding exercise bike & Getting out of bath tub \\
\hline Getting up from the floor & Bridge exercise & Getting out of tub \\
\hline Getting on floor & Stretching quads & Tub bathing \\
\hline \multicolumn{3}{|l|}{ Sitting on ground } \\
\hline Walking Up/Down Hills & Yard Work & Climbing Ladder \\
\hline Walking down hills & Working in the yard & Step ladder \\
\hline Going down grades & Gardening & Climbing ladder \\
\hline Down ramp or hill & Doing yard work & \\
\hline Down hills & Squatting-garden & \\
\hline \multicolumn{3}{|l|}{ Walking down hills } \\
\hline Driving & Lying in Bed & Managing Environment \\
\hline Driving too long & Sleeping & Walking around students \\
\hline \multirow[t]{2}{*}{ Driving } & Lying in bed & Stepping over things \\
\hline & & Uneven surface \\
\hline Bed Transfer & Carrying Objects Up/Down Stairs & Gait Initiation \\
\hline Rolling over in bed & Carrying things on stairs & Get bearing before starting to walk \\
\hline Getting out of bed & Carrying groceries up steps & Stand up and walk \\
\hline Balance & Up/Down Curbs & Toilet Transfer \\
\hline Losing balance & Up/down curbs & Getting from toilet seat \\
\hline
\end{tabular}

Table 3. COPM Activity Categories Mapped to WOMAC-PF Items by Frequency of Identification

\begin{tabular}{|c|c|c|c|c|c|c|c|c|c|c|}
\hline \multicolumn{5}{|c|}{ COPM } & \multicolumn{6}{|c|}{ WOMAC-PF } \\
\hline \multirow{2}{*}{$\begin{array}{l}\text { Activity } \\
\text { Category }\end{array}$} & \multirow{2}{*}{$\begin{array}{c}\text { Frequency } \\
\text { (\%) }\end{array}$} & \multicolumn{3}{|c|}{ Mean Raw Scores } & \multirow{2}{*}{ Item } & \multicolumn{5}{|c|}{ Frequency of Functional Limitation (\%) } \\
\hline & & Importance & Performance & Satisfaction & & None & Mild & Moderate & Severe & Extreme \\
\hline Down Stairs & $26(52)$ & 9.08 & 4.62 & 3.1 & $\begin{array}{l}\text { Descending } \\
\text { Stairs }\end{array}$ & $7(14)$ & $12(24)$ & $23(46)$ & $7(14)$ & $1(2)$ \\
\hline Up Stairs & $22(44)$ & 9.36 & 4.95 & 3.48 & $\begin{array}{l}\text { Ascending } \\
\text { Stairs }\end{array}$ & $9(18)$ & $20(40)$ & $18(36)$ & $3(6)$ & $0(0)$ \\
\hline Standing & $19(38)$ & 7.84 & 5.42 & 3.37 & Standing & $18(36)$ & $15(30)$ & $14(28)$ & $3(6)$ & $0(0)$ \\
\hline $\begin{array}{l}\text { Sit-to-Stand } \\
\text { Transfer }\end{array}$ & $18(36)$ & 9.06 & 4.39 & 3.39 & $\begin{array}{l}\text { Rising from } \\
\text { Sitting }\end{array}$ & $7(14)$ & $16(32)$ & $23(46)$ & $2(4)$ & $2(4)$ \\
\hline Kneeling & $16(32)$ & 6.63 & 2.31 & 2 & $\mathrm{~N} / \mathrm{M}$ & - & - & - & - & - \\
\hline Walking & $14(28)$ & 7.36 & 4.5 & 4.14 & $\begin{array}{l}\text { Walking on } \\
\text { Flat } \\
\text { Surface }\end{array}$ & $20(40)$ & $23(46)$ & 7 (14) & $0(0)$ & $0(0)$ \\
\hline Squatting & $12(24)$ & 6.75 & 3.08 & 2.42 & $\mathrm{~N} / \mathrm{M}$ & - & - & - & - & - \\
\hline $\begin{array}{l}\text { Bending/ } \\
\text { Flexibility }\end{array}$ & $10(20)$ & 8.4 & 4.5 & 3.5 & $\begin{array}{l}\text { Bending to } \\
\text { Floor }\end{array}$ & $8(16)$ & $15(30)$ & $20(40)$ & $6(12)$ & $1(2)$ \\
\hline
\end{tabular}




\begin{tabular}{|c|c|c|c|c|c|c|c|c|c|c|}
\hline Car Transfer & $10(20)$ & 8.7 & 5.9 & 4 & $\begin{array}{l}\text { Getting In/ } \\
\text { Out of Car }\end{array}$ & $13(26)$ & $22(44)$ & $13(26)$ & $1(2)$ & $1(2)$ \\
\hline $\begin{array}{l}\text { Carrying/ } \\
\text { Lifting Items }\end{array}$ & 7 (14) & 8.29 & 5.43 & 4.43 & $\mathrm{~N} / \mathrm{M}$ & - & - & - & - & - \\
\hline Sitting & 7 (14) & 6.86 & 5.57 & 3.57 & Sitting & $26(52)$ & $12(24)$ & $11(22)$ & $1(2)$ & $0(0)$ \\
\hline \multirow[t]{2}{*}{$\begin{array}{l}\text { Dressing/ } \\
\text { Socks }\end{array}$} & $6(12)$ & 7.67 & 5.17 & 3.67 & $\begin{array}{l}\text { Putting on } \\
\text { Socks }\end{array}$ & $18(36)$ & $18(36)$ & $10(20)$ & $4(8)$ & $0(0)$ \\
\hline & & & & & $\begin{array}{l}\text { Taking Off } \\
\text { Socks }\end{array}$ & $19(38)$ & $22(44)$ & 7 (14) & $2(4)$ & $0(0)$ \\
\hline \multirow{2}{*}{$\begin{array}{l}\text { Household } \\
\text { Chores/ } \\
\text { Recreational } \\
\text { Activity }\end{array}$} & $6(12)$ & 8 & 5.5 & 3.67 & $\begin{array}{l}\text { Light } \\
\text { Domestic } \\
\text { Duties }\end{array}$ & $18(36)$ & $25(50)$ & 7 (14) & $0(0)$ & $0(0)$ \\
\hline & & & & & $\begin{array}{l}\text { Heavy } \\
\text { Domestic } \\
\text { Duties }\end{array}$ & $6(12)$ & $15(30)$ & $25(50)$ & $4(8)$ & $0(0)$ \\
\hline \multirow[t]{2}{*}{$\begin{array}{l}\text { Household } \\
\text { Chores/ } \\
\text { Recreational } \\
\text { Activity }\end{array}$} & $6(12)$ & 8 & 5.5 & 3.67 & $\begin{array}{l}\text { Light } \\
\text { Domestic } \\
\text { Duties }\end{array}$ & $18(36)$ & $25(50)$ & 7 (14) & $0(0)$ & $0(0)$ \\
\hline & & & & & $\begin{array}{l}\text { Heavy } \\
\text { Domestic } \\
\text { Duties }\end{array}$ & $6(12)$ & $15(30)$ & $25(50)$ & $4(8)$ & $0(0)$ \\
\hline $\begin{array}{l}\text { Strength/ } \\
\text { Endurance }\end{array}$ & $6(12)$ & 9.33 & 4.5 & 3.33 & $\mathrm{~N} / \mathrm{M}$ & - & - & - & - & - \\
\hline $\begin{array}{l}\text { Floor } \\
\text { Transfer }\end{array}$ & $5(10)$ & 7.8 & 2.8 & 2.6 & $\mathrm{~N} / \mathrm{M}$ & - & - & - & - & - \\
\hline $\begin{array}{l}\text { Lower } \\
\text { Extremity } \\
\text { Exercise }\end{array}$ & $5(10)$ & 8.4 & 7.4 & 8 & $\mathrm{~N} / \mathrm{M}$ & - & - & - & - & - \\
\hline Tub Transfer & $5(10)$ & 9.6 & 3.4 & 2.2 & $\begin{array}{l}\text { Getting In/ } \\
\text { Out of Bath }\end{array}$ & $18(36)$ & $17(34)$ & $12(24)$ & $3(6)$ & $0(0)$ \\
\hline $\begin{array}{l}\text { Walking Up/ } \\
\text { Down Hills }\end{array}$ & $5(10)$ & 7 & 5.4 & 4.8 & $\mathrm{~N} / \mathrm{M}$ & - & - & - & - & - \\
\hline Yard Work & $4(8)$ & 7.25 & 5.25 & 4.75 & $\mathrm{~N} / \mathrm{M}$ & - & - & - & - & - \\
\hline $\begin{array}{l}\text { Climbing } \\
\text { Ladder }\end{array}$ & $3(6)$ & 5.33 & 4.33 & 4 & $\mathrm{~N} / \mathrm{M}$ & - & - & - & - & - \\
\hline Driving & $3(6)$ & 8 & 3.67 & 2 & $\mathrm{~N} / \mathrm{M}$ & - & - & - & - & - \\
\hline Lying in Bed & $3(6)$ & 10 & 2.67 & 2 & $\begin{array}{l}\text { Lying in } \\
\text { Bed }\end{array}$ & $25(50)$ & $17(34)$ & 7 (14) & $1(2)$ & $0(0)$ \\
\hline Managing & $3(6)$ & 8.33 & 5.67 & 3.67 & $\mathrm{~N} / \mathrm{M}$ & - & - & - & - & - \\
\hline Bed Transfer & $2(4)$ & 7.5 & 5.5 & 4.5 & $\begin{array}{l}\text { Rising from } \\
\text { Bed }\end{array}$ & $14(28)$ & $14(28)$ & $10(20)$ & $2(4)$ & $0(0)$ \\
\hline $\begin{array}{l}\text { Carrying } \\
\text { Objects Up/ } \\
\text { Down Stairs }\end{array}$ & $2(4)$ & 7.5 & 3 & 3 & $\mathrm{~N} / \mathrm{M}$ & - & - & - & - & - \\
\hline $\begin{array}{l}\text { Gait } \\
\text { Initiation }\end{array}$ & $2(4)$ & 10 & 5 & 1 & $\mathrm{~N} / \mathrm{M}$ & - & - & - & - & - \\
\hline Balance & $1(2)$ & 8 & 7 & 7 & $\mathrm{~N} / \mathrm{M}$ & - & - & - & - & - \\
\hline $\begin{array}{l}\text { Up/Down } \\
\text { Curbs }\end{array}$ & $1(2)$ & 10 & 6 & 3 & $\mathrm{~N} / \mathrm{M}$ & - & - & - & - & - \\
\hline $\begin{array}{l}\text { Toilet } \\
\text { Transfer }\end{array}$ & $1(2)$ & 8 & 6 & 6 & $\begin{array}{l}\text { Getting } \\
\text { On/Off } \\
\text { Toilet }\end{array}$ & $15(30)$ & $19(38)$ & $15(30)$ & $1(2)$ & $0(0)$ \\
\hline
\end{tabular}

Citation: Disantis AY, Piva SR, Irrgang JJ (2018) Standardized Patient Reported Outcomes Do Not Capture Functional Deficits of 


\begin{tabular}{|l|l|l|l|l|l|l|l|l|l|}
\hline N/I & - & - & - & - & $\begin{array}{l}\text { Going } \\
\text { Shopping }\end{array}$ & $15(30)$ & $18(36)$ & $16(32)$ & $1(2)$ \\
\hline
\end{tabular}

COPM- Canadian Occupational Performance Measure. The COPM importance scale is rated as 1 (not important at all) to 10 (extremely important), the performance scale is rated as 1 (not able to do it) to 10 (able to do it extremely well), and the satisfaction scale is rated as 1 (not satisfied at all) to 10 (extremely satisfied).

WOMAC-PF- Western Ontario and McMaster Universities Osteoarthritis Index Physical Function subscale.

The top rows of the table (shaded cells) depict the activities identified by at least $10 \%$ of participants in the COPM.

The bottom rows (not shaded cells) represent the activities with identification by less than 10\% of participants in the COPM.

N/M - No Match. The empty cells on the right side of the table represent an activity category identified in the COPM without a matched item on the WOMAC-PF.

N/I - No Identification. The empty cells on the left side of the table represent activity included on the WOMAC-PF but not identified by participants on the COPM.

activities identified by less than $10 \%$ of participants (not shaded rows in Table 3) were not statistically significant nor clinically meaningful, indicating that the activities more frequently identified were not more germane to participants than those identified less frequently. The means of importance scores for activities more frequently identified and less frequently identified were $8.2 \pm 0.9$ and $8.2 \pm 1.4(\mathrm{t}=.000, \mathrm{p}=1.000)$ respective. The means of performance scores for activities more and less frequently identified were $4.7 \pm 1.2$ and $4.9 \pm 1.4$ respectively $(\mathrm{t}=.434, \mathrm{p}=0.668)$. Last, the means of satisfaction scores for activities more and less frequently identified were $3.7 \pm 1.3$ and $3.7 \pm 1.8$ respectively $(\mathrm{t}=.118, \mathrm{p}=0.907)$ (these averages are not shown in Table 3).

Among the 19 categories more frequently identified in the COPM, 7 were unable to be matched to a corresponding WOMAC-PF item(kneeling, squatting, carrying/lifting, strength/ endurance, floor transfer, lower extremity exercise, and walking up/down hills) while 12 were matched to the WOMAC-PF. For the 12 activities matched to the WOMAC-PF, the percentage of participants that identified the activity in the COPM and the percentage of participants that rated that activity as at least moderately limited in the same item in the WOMAC-PF (in the Likert scale) were relatively similar for ascending and descending stairs, standing, sit-to-stand transfer, walking, bending/ flexibility, car transfer, and sitting. For example, identification in the WOMAC-PF and COPM respectively were $62 \%$ and 52\% for descending stairs, $34 \%$ and $44 \%$ for ascending stairs, and $54 \%$ and $36 \%$ for standing. However, those percentages were more than doubled in the WOMAC-PF than for the COPM for activities such as bending (WOMAC-PF 54\% and COPM 20\%), dressing/ socks (WOMAC-PF 28\% and COPM 12\%) household/recreational activity (WOMAC-PF 58\% and COPM 12\%) and tub transfer (WOMAC-PF $30 \%$ and COPM 10\%). Among the 11 activities with low frequency of identification on the COPM (Table 3, no shaded rows), 8 were not represented on the WOMAC-PF. Additionally, the item going shopping from the WOMAC-PF was not identified by participants on the COPM.

\section{Discussion}

Following TKR, patients face challenges with both basic activities of daily living as well as with higher-level functional activities. Our results demonstrate that the functional activities captured by the WOMAC-PF do not encompass many of the functional limitations experienced following TKR. From the 30 activities identified by participants as important to them, only 15 were included as an item question on the WOMAC-PF. This corresponds to an underrepresentation of $50 \%$ of the patientselected functional activity deficits that persist following TKR. Many of these under-represented activity categories align with more physically demanding activities that have been identified in the literature as problematic to most patients following TKR (16, 17).

In the current study, COPM scores were also used to assess how relevant the patients judged the activities listed or not on the WOMAC-PF. The results demonstrated that the activity categories reported on the COPM that were represented in the WOMAC-PF had similar scores of importance, performance, and satisfaction, as compared to the activities not represented in the WOMAC-PF; meaning that the activities not represented are equally relevant and patient-centric. We also observed that activities identified by at least $10 \%$ of participants in the COPM had similar scores of importance, performance, and satisfaction as compared to the activities with less than $10 \%$, suggesting that the activities less frequently identified were no less important than those chosen more frequently. These findings are relevant because the activity categories that are not represented in the WOMAC-PF are equally important to patients and should be considered for PROMs in TKR.

Although the results of this study suggest that the WOMAC-PF under represents the functional limitations experienced after TKR, we do not suggest replacing the WOMAC with the COPM or other standardized outcome measures, as they will likely carry similar limitations. For example, other patient-specific function scale such as the COPM, while have the advantage to enable patients to identify their activity limitations without being restricted to standardized or pre-determined items, disadvantages include the inability to compare (1) scores across participants because each participant self-selects different activity limitations, and (2) progress overtime because patients may select different activities upon re-evaluation. In terms of the other standardized PROMs, the same limitations that affect the WOMAC likely affect other widely used questionnaires. For example, the nonproprietary KOOS was developed as an extension of the WOMAC for younger and more active patients $(8,19)$. However, the 17 items on KOOS that form the subscale of function during daily living are the same as the WOMAC-PF, and, among the 5 items that form the subscale of function during sports and recreational 
activities, only 2 items (squatting and kneeling) were mentioned by participants as being germane to them; the other 3 activities (running, jumping, twisting/pivoting on your injured knee) tend to be contra indicated after TKR. Last, standardized PROMs that assess physical function tend to be burdensome for respondents because of the large number of questions (WOMAC-PF, 17 questions; KOOS-PF, 22 questions).

We believe that a better alternative to overcome the limitations of largely used proms in TKR is the use of computer adaptive testing (CAT). Unlike standardized outcome measures with pre-determined items that will inevitably fail to capture the full spectrum of functional limitations, or patient-specific functional scales that don't enable meaningful comparison across patients, CAT uses a computer algorithm that selects and administers items targeted to the person's unique level of physical function enabling more efficient and precise measurement $(27,28)$. These test items are selected from a bank that includes both sedentary, such as sitting for a long period, and strenuous activities, such as running for a mile. Each patient is presented only those items that are appropriate for her level of function and items that are either too "easy" or "hard" for the patient are not administered. Based on the response to previous questions, the CAT system assigns the next question using item response theory, to expose a minimum set of relevant questions to the respondent and to create a summary score for the domain. Thus, it minimizes questionnaire burden and avoids floor and ceiling effects $(27,28)$. An example of computer adaptive tests to measure physical function is the Patient Reported Outcomes Measurement Information System (PROMIS) Physical Function Scale, funded by the US National Institutes of Health (29). Future efforts should compare the use of CAT surveys with standardized legacy proms in TKR and determine outcome norms for patients at specific time intervals after TKR before widely adoption in clinical practice.

The activities listed by participants in the COPM but not endorsed in the WOMAC-PF included mainly higher-level or demanding tasks, such as carrying items up and down stairs, kneeling, squatting, floor transfers, and walking up/down hills and around objects. Bourne et al. Investigated the reason for dissatisfaction in patients following TKR and found that most patients were dissatisfied secondary to not meeting their high post-operative functional expectations (30). It has been found that in general, health care professionals do not assess functional deficits during high-level tasks; instead, their focus has been on joint stability, range of motion, and basic activities of daily living (31). In the population of patients that undergo contemporary TKR, it is reported that $75 \%$ of patients expect to be pain free and $40 \%$ expect not to have limitations in more demanding activities (32). The activities that are important to patients receiving TKR may not resemble those activities identified in PROMs developed several decades ago. While standardized PROMs of physical function accurately reflected a less active population at a time when the surgical procedures and pathways of care post-op were not as developed as today, and expectations were set low, this does not seem to be the case any longer. Because patients receiving TKR today are younger, generally more active, and have higher expectations for functional outcomes post operatively, it stands to reason that the outcome measures being used should parallel these changes.

There are limitations to the current study. Participants were included if they had TKR between 3 and 6 months prior and, because of that, it can be argued that the results are not generalizable to those immediately after TKR. However, the studies that first questioned the value of WOMAC-PF following TKR were in patients immediately after the surgery and up to a couple of months after that $(8,9)$. Therefore, it seems that the underrepresentation of the WOMAC-PF spans from early post-op to several months after TKR. Additionally, this study proposed secondary analysis of data collected by the parent study and, as such, we did not predetermine requirements for sample size. Although the sample size was relatively small, the negligible differences in COPM scores (i.e., between matched and unmatched items and between more and less frequently identified items) would rebut the possibility that type 2 error would have occurred in the few statistical tests used in the study. Regardless of the limitations, the study results build on prior literature establishing limitations of the PROMs widely in use and provides a new perspective to the topic.

\section{Conclusions}

With PROMs being utilized frequently in both clinical practice and research, it is of utmost importance that these tools accurately represent activities that are important to the population at hand. While the WOMAC-PF captures a large number of problematic activities important to patients, it under represents a certain subset of activities that are activity limitations relevant to today's TKR population. Results of the present study question the utilization of proms, such as the WOMAC-PF, in patients that received contemporary TKR procedures. A viable alternative could be computerized adaptive measures that are founded in the item response theory, making the content relevant for each individual patient regardless of being in the low or high spectrum of functional limitation.

\section{Acknowledgement}

\section{ClinicalTrials.gov Identifier: NCT01799772}

This study was supported by the National Center for Medical Rehabilitation Research (NCMRR) (1 K01 HD 058035) and the University of Pittsburgh Medical Center-Rehabilitation Institute, and the Pepper Center Scholars Pilot Program (P30AG024827). The sources of financial support played no role in the investigation. There were no other sources of support for this study. Financial interests of the authors do not create a potential or apparent conflict of interest regarding the work.

\section{References}

1. Kurtz SM, Ong KL, Schmier J. Primary and revision arthroplasty surgery caseloads in the United States from 1990 to 2004. J Arthroplasty. 2009;24(2):195-203.

2. Parvizi J, Nunley RM, Berend KR, Lombardi AV, Ruh EL, Clohisy JC, et al. High level of residual symptoms in young patients after total knee 
arthroplasty. Clin Orthop Relat Res. 2014;472(1):133-137.

3. Lützner J, Hübel U, Kirschner S, Günther KP, Krummenauer F. Long-term results in total knee arthroplasty: a meta-analysis of revision rates and functional outcome. Chirurg. 2011;82(7):618-624.

4. Collins NJ, Misra D, Felson DT, Crossley KM, Roos EM. Measures of knee function. International Knee Documentation Committee (IKDC) Subjective Knee Evaluation Form, Knee Injury and Osteoarthritis Outcome Score (KOOS), Knee Injury and Osteoarthritis Outcome Score Physical Function Short Form (KOOS-PS), Knee Outcome Survey Activities of Daily Living Scale (KOS-ADL), Lysholm Knee Scoring Scale, Oxford Knee Score (OKS), Western Ontario and McMaster Universities Osteoarthritis Index (WOMAC), Activity Rating Scale (ARS), and Tegner Activity Score (TAS). Arthrit Care Res. 2011;63(11):208-228.

5. Bellamy N (2014). WOMAC Osteoarthritis Index: user guide XI. Brisbane, Australia.

6. Angst F, Aeschlimann A, Steiner W, Stucki G. Responsiveness of the WOMAC osteoarthritis index as compared with the SF-36 in patients with osteoarthritis of the legs undergoing a comprehensive rehabilitation intervention. Ann Rheum Dis. 2001;60(9):834-840.

7. Maly MR, Costigan PA, and Onley SJ. Determinants of self-reported outcome measures in people with knee osteoarthritis. Arch Phys Med Rehabil. 2006;87(1):96-104.

8. Roos EM, Toksvig-Larsen S. Knee injury and Osteoarthritis Outcome Score (KOOS) - validation and comparison to the WOMAC in total knee replacement. Health and Quality of Life Outcomes. 2003;1:17.

9. Parent, E and Moffet, H. Comparative responsiveness of locomotor tests and questionnaires used to follow early recovery after total knee arthroplasty. Arch Phys Med Rehabil. 2002;83(1):70-80.

10. Stratford PW, Kennedy DM. Does parallel item content on WOMAC's pain and function subscales limit its ability to detect change in functional status? BMC Musculoskeletal Disorders. 2004; 5(17).

11. Terwee CB, van der Sikke RMA, van Lummel RC, Benink RJ, Meijers WG, de Vet HC. Self-reported physical functioning was more influenced by pain than performance-based physical functioning in kneeosteoarthritis patients. J Clin Epidemiol. 2006;59(7):724-731.

12. Woolhead GM, Donovan JL, Dieppe PA. Outcomes of total knee replacement: a qualitative study. Rheumatology (Oxford). 2005; 44(8):1032-1037.

13. Stratford PW, Kennedy DM, and Woodhouse LJ. Performance measures provide assessments of pain and function in people with advanced osteoarthritis of the hip or knee. Phys Ther. 2006;86(11):1489-1496.

14. Kennedy D, Stratford PW, Pagura SMC, et al. Exploring the factorial validity and clinical interpretability of the Western Ontario and McMaster Universities Osteoarthritis Index (WOMAC). Physiother Can. 2003;55(3):160-168.

15. Faucher M, Poiraudeau S, Lefevre-Colau MM, Rannou F, Fermanian J, Revel M. Algo-functional assessment of knee osteoarthritis: comparison of the test-retest reliability and construct validity of the WOMAC and Lequesne indexes. Osteoarthritis Cartilage. 2002;10(8):602-610.
16. Noble PC, Gordon MJ, Weiss JM, Reddix RN, Conditt MA, Mathis KB. Does total knee replacement restore normal knee function? Clin Orthop Relat Res. 2005;431:157-165

17. Dobson F, Hinman RS, Roos, EM, Abbott JH, Stratford P, Davis AM, et al. OARSI recommended performance-based tests to assess physical function in people diagnosed with hip or knee osteoarthritis. Osteoarthr Cartilage. 2013;21(8):1042-1052.

18. Bellamy N, Buchanan WW. A preliminary evaluation of the dimensionality and clinical importance of pain and disability in osteoarthritis of the hip and knee. Clin Rheumatol. 1986;5(2):231241.

19. Roos EM, Roos HP, Lohmander LS, Ekdahl C, Beynnon BD. Knee Injury and Osteoarthritis Outcome Score (KOOS)-development of a self-administered outcome measure. J Orthop Sports Phys Ther. 1998;28(2):88-96.

20. Piva SR, Almeida GJ, Gil AB, DiGioia AM, Helsel DL, Sowa GA. A comprehensive behavioral and exercise intervention improves physical function and activity participation after total knee replacement - a pilot randomized study. Arthritis Care Res (Hoboken). 2017;69(12):1855-1862.

21. Bellamy N, Buchanan WW, Goldsmith $\mathrm{CH}$, et al. Validation study of WOMAC: a health status instrument for measuring clinically important patient relevant outcomes to anti rheumatic drug therapy in patients with osteoarthritis of the hip or knee. J Rheumatol. 1992; 19:153-159.

22. Hawker G, Melfi C, Paul J, Green R, Bombardier C. Comparison of a generic (SF-36) and a disease specific (WOMAC) (Western Ontario and McMaster Universities Osteoarthritis Index) instrument in the measurement of outcomes after knee replacement surgery. J Rheumatol. 1995;22(6):1193-1196.

23. Escobar A, Quintana JM, Bilbao A, Arostegui I, Lafuente I, Vidaurreta I. Responsiveness and clinically important differences for the WOMAC and SF-36 after total knee replacement. Osteoarthritis and Cartilage. 2006;15(3):273-280.

24. Law M, Baptiste S, McColl M, Opzoomer A, Polatajko H, Pollock N. The Canadian Occupational Performance Measure: an outcome measure for occupational therapy. Can J Occup Ther. 1990;57(2):82-87.

25. Law M, Baptiste S, Carswell A, McColl MA, Polatajko H, Pollock N (2014). Canadian Occupational Performance Measure (COPM) (5th ed). COAT Publications ACE.

26. Van der Linden ML, Kumaran BR, Wade FA, Nutton RW. The Canadian Occupational Performance Measure Before and After Total Knee Arthroplasty, Which Activities do Patients Rate as Important? Journal of Bone \& Joint Surgery, British Volume. 2012;94(24).

27. Cella D, Chang CH. A discussion of item response theory and its applications in health status assessment. Med Care. 2000;38(9):11661672.

28. Fliege H, Becker J, Walter OB, Bjorner JB, Klapp BF, Rose M. Development of a computer-adaptive test for depression (D-CAT). Qual Life Res. 2005;14(10):2277-2291.

29. Cella D, Yount S, Rothrock N, Gershon R, Cook K, Reeve B. The Patient 
Reported Outcomes Measurement Information System (PROMIS) Progress of an NIH roadmap cooperative group during its first two years. Med Care. 2007;45(5):3-11.

30. Bourne RB, Davis AM, Charron KDJ. Patient satisfaction after total knee arthroplasty: who is satisfied and who is not? Clin Orthop Relat Res. 2010;468(1):57-63.
31. Katz JN, Phillips CB, Baron JA, Fossel AH, Mahomed NN, Barrett J. Association of hospital and surgeon volume of total hip replacement with functional status and satisfaction three years following surgery. Arthritis Rheum. 2003;48(2):560-568.

32. Noble PC, Conditt MA, Cook KF. The John Insall Award: Patient expectations affect satisfaction with total knee arthroplasty. Clin Orthop Relat Res. 2006;452:35-43. 